\title{
Conservação de maçã minimamente processada com o uso de películas comestíveis
}

\author{
Preservation of minimally processed apple using edible coatings \\ Luciana Cristina Brigatto FONTES ${ }^{1}$, Silene Bruder Silveira SARMENTO ${ }^{2 *}$, \\ Marta Helena Fillet SPOTO ${ }^{2}$, Carlos Tadeu dos Santos DIAS ${ }^{3}$
}

\section{Resumo}

O objetivo do trabalho foi avaliar o efeito de películas comestíveis na conservação de maçãs da cultivar Royal Gala Minimamente Processadas (MP) durante armazenamento refrigerado por 13 dias. Os tratamentos foram: o controle, a solução conservadora (1\% ácido ascórbico; $0,5 \%$ ácido cítrico; $0,7 \% \mathrm{NaCl} ; 0,25 \% \mathrm{CaCl}_{2}$ ) e as películas [dextrina (5,5\%), fécula de mandioca (3\%) e alginato de sódio $(2 \%) \mathrm{com} \mathrm{CaCl}_{2}(0,6 \%)$ ]. A solução conservadora reduziu a taxa respiratória e a produção de etileno em relação ao controle e promoveu maior claridade da polpa. Os tratamentos com películas apresentaram redução média de $38 \%$ na taxa respiratória e mais de $50 \%$ na produção de etileno em relação ao controle, sendo o alginato o mais eficiente. A película de alginato apresentou maior umidade no início do armazenamento, igualandose aos demais tratamentos no $9^{\circ}$ dia. No tratamento controle, os valores de firmeza dos tecidos diminuíram com o armazenamento e nos demais tratamentos, a tendência foi oposta. Maçãs com alginato apresentaram menor acidez e coloração mais escura dentre os tratamentos, respectivamente, em função do $\mathrm{pH}$ e da coloração da própria solução filmogênica.

Palavras-chave: maçã; processamento mínimo; películas comestíveis.

\begin{abstract}
The effect of edible coatings on the preservation of the Minimally Processed (MP) Royal Gala apples under refrigerated storage for 13 days was studied. The treatments were: the control solution, preserving solution ( $1 \%$ of acid ascorbic; $0,5 \%$ of citric acid; $0,7 \%$ of $\mathrm{NaCl} ; 0,25 \%$ of $\mathrm{CaCl}_{2}$ ), manioc starch (3\%), and sodium alginate (2\%) with $\mathrm{CaCl}_{2}$. The preserving solution decreased the respiratory and the ethylene production rate and showed a lighter pulp. The coatings decreased the respiratory rate by $38 \%$ and the ethylene production by $50 \%$. The alginate was the most efficient, and it presented a better retention of moisture up to the 9th day of storage. The control presented less firmness at during storage, but the other treatments presented the opposite. Apples with alginate presented less acidity and a darker coloration because of the $\mathrm{pH}$ and the coloration of the filmogenic solution.

Keywords: apple, minimal processing, edible coating.
\end{abstract}

\section{Introdução}

Uma tendência crescente na atualidade são os vegetais Minimamente Processados (MP), ou seja, frutas e hortaliças que tenham sido submetidas a qualquer alteração física que mantenha seu estado fresco. Este processamento inclui as operações de seleção, lavagem, sanitização, descascamento, corte, centrifugação, embalagem, armazenamento e comercialização (MORETTI, 1999).

As alterações por deterioração fisiológica nos MP ocorrem especialmente devido às injúrias nos tecidos, geralmente reduzindo o período de conservação. Essas injúrias nos tecidos vegetais resultam da manipulação e processamento, como os danos mecânicos, que promovem contato maior entre as enzimas e substratos, induzindo reações enzimáticas indesejáveis, perda de íons e de outros compostos celulares e perda de umidade. Muitos vegetais defendem-se aumentando a respiração, a produção de etileno, a atividade das enzimas responsáveis pelo escurecimento e o desenvolvimento de sabores e odores desagradáveis, além do amolecimento dos tecidos (BALDWIN; NISPEROS-CARRIEDO; BAKER, 1995).

Gil et al. (1998) relataram que, em maçãs da variedade Fuji minimamente processadas, o uso de atmosfera livre de oxigênio associado à imersão em ácido ascórbico foi efetivo no controle do escurecimento enzimático. Os mesmos autores não recomendam o uso isolado da atmosfera livre de oxigênio em função de seu efeito sobre as características organolépticas e segurança microbiológica das maçãs, sugerindo novos estudos nesse sentido. Em maçãs minimamente processadas, o escurecimento enzimático é a principal causa de deterioração.

Wong et al. (1994) propuseram o uso de solução conservadora (ácido ascórbico, ácido cítrico, cloreto de cálcio e cloreto de sódio) para vegetais MP. As principais funções esperadas desta solução são evitar ou minimizar o escurecimento dos tecidos, a perda do aroma e do sabor, mudanças na textura, redução na qualidade nutricional, além de propriedades antimicrobianas.

2 Departamento Agroindústria, Alimentos e Nutrição, Escola Superior de Agricultura Luiz de Queiroz - ESALQ, Universidade de São Paulo - USP, Av. Pádua Dias, 11, Agronomia, CEP 13418-900, Piracicaba - SP, Brasil, E-mail: sbssarme@esalq.usp.br

${ }^{3}$ Departamento de Ciências Exatas, Escola Superior de Agricultura Luiz de Queiroz - ESALQ, Universidade de São Paulo - USP

${ }^{*}$ A quem a correspondência deve ser enviada 
Outro método para aumentar a vida pós-colheita de vegetais é o uso de coberturas comestíveis, definidas como uma fina camada de material comestível, depositada em um alimento como revestimento. Sua finalidade é inibir ou reduzir a migração de umidade, de oxigênio, de dióxido de carbono e de aromas, pois promovem barreiras semipermeáveis (KROCHTA; MULDER-JOHNSTON, 1997).

Para maçãs minimamente processadas o uso de coberturas comestíveis (carragena, proteína concentrada de trigo) em combinação com agentes antioxidantes (ácido ascórbico, ácido cítrico e ácido oxálico) foi eficiente para prolongar a vida útil por duas semanas quando armazenadas a $3{ }^{\circ} \mathrm{C}$ (LEE et al., 2003).

Revestimentos de quitosana utilizados em pedaços de manga foram eficientes para retardar a perda de água e o crescimento microbiano, estendendo a vida útil da fruta minimamente processada (CHIEN; SHEU; YANG, 2007). Estudando o uso de películas de fécula de mandioca sobre abacaxis em pedaços, VIEIRA (2000) observou variações inexpressivas nos índices de sólidos solúveis, acidez, $\mathrm{pH}$, perda de massa fresca e textura do produto final armazenado por 7 dias.

Trabalhos na literatura sobre a utilização de películas comestíveis em vegetais inteiros mostram resultados positivos para dextrina como barreira à umidade em amêndoas (KROCHTA; MULDER-JOHNSTON, 1997), para alginato de sódio como controlador da perda de umidade em bulbos de alho (NUSSINOVITCH; HERSHKO, 1996) e para fécula de mandioca como barreira ao oxigênio em goiaba (OLIVEIRA, 1996).

O objetivo do presente trabalho foi avaliar o uso de películas comestíveis, em associação com solução conservadora, na preservação de maçãs da cultivar Royal Gala MP durante armazenamento refrigerado.

\section{Material e métodos}

\subsection{Material}

As maçãs utilizadas foram da cultivar Royal Gala, cedidas pela Cooperativa Regional Agropecuária Serrana (COOPERSERRA), Estado de Santa Catarina. A solução conservadora usada foi composta de ácido ascórbico (1\%), ácido cítrico $(0,5 \%), \mathrm{CaCl}_{2}(0,25 \%)$ e $\mathrm{NaCl}(0,7 \%)$ e os produtos (películas) dextrina de fécula de mandioca e fécula de mandioca, cedidos pela National Starch, São Paulo-SP e alginato de sódio, cedido pela FMC BioPolymer, Limeira-SP.

\subsection{Métodos}

\section{Preparo das maçãs MP}

As maçãs selecionadas foram primeiramente lavadas, descascadas, sanitizadas e cortadas manualmente em cubos de aproximadamente $2 \times 2 \mathrm{~cm}$ com auxílio de facas de aço inoxidável.

Foram utilizados 5 tratamentos, dentre os quais o controle, que constou de maçãs cortadas (MP). O segundo tratamento constou de maçãs MP e imersas imediatamente em solução conservadora contendo ácido ascórbico (1\%), ácido cítrico $(0,5 \%)$, cloreto de cálcio $(0,25 \%)$ e cloreto de sódio $(0,7 \%)$, por 2 minutos.

Nos tratamentos com revestimentos, as maçãs MP foram tratadas primeiramente com solução conservadora (2 minutos), e posteriormente imersas na solução formadora de película (2 minutos). As maçãs assim tratadas seguiram para secagem, realizada com auxílio de ventilador, em ambiente refrigerado $\left(15^{\circ} \mathrm{C}\right)$ por 30 minutos. $\mathrm{O}$ material foi acondicionado em bandejas $(13 \times 18 \mathrm{~cm})$ de poliestireno, envoltas em filme de PVC (21,3 $\mu \mathrm{m}$ de espessura). Em cada bandeja foram acondicionados 16 pedaços de maçã MP (peso médio $100 \mathrm{~g} /$ bandeja) que foram mantidas sob refrigeração em câmara fria $\left(2{ }^{\circ} \mathrm{C}\right.$ e $40 \%$ UR) por até 13 dias.

O tratamento com dextrina de fécula de mandioca foi realizado na concentração de 5,5\%. A dextrina foi solubilizada em água destilada mediante aquecimento a $70^{\circ} \mathrm{C}$, sob agitação constante, e posteriormente resfriada até $15^{\circ} \mathrm{C}$.

No tratamento com fécula de mandioca, foi utilizada suspensão a $3 \%$ e aquecimento a $70{ }^{\circ} \mathrm{C}$, sob agitação constante $\mathrm{e}$ posterior resfriamento até $15^{\circ} \mathrm{C}$.

No tratamento com alginato de sódio, as maçãs MP receberam primeiramente a aplicação de solução de cloreto de cálcio a $0,6 \%$, para promover a geleificação do alginato de sódio a $2 \%$ aplicado. A solubilização do alginato de sódio foi previamente realizada em água com o aquecimento da suspensão até $70^{\circ} \mathrm{C}$ e posterior resfriamento até $15^{\circ} \mathrm{C}$.

\section{Avaliação das maçãs MP}

Um corte fino da superfície do pedaço de maçã MP com 1 dia de armazenamento foi realizado com auxílio de lâmina inoxidável. Este material foi fixado em stubs utilizando-se fitas adesivas de dupla face e recoberto com ouro (40-50 nm) por 210 segundos em metalizador da marca Balzers. O material foi observado em microscópio eletrônico de varredura (Zeiss - DSM 940 A).

Para quantificar o $\mathrm{CO}_{2}$ liberado pelas maçãs inteiras ou minimamente processadas, estas foram acondicionadas em frascos $(600 \mathrm{~mL})$ de vidro. Foram utilizadas 5 repetições de cada tratamento, com aproximadamente $120 \mathrm{~g}$ de maçã por frasco. Os frascos, tampados com filme PVC, foram armazenados por 13 dias em câmara fria, a $2^{\circ} \mathrm{C}$. Foram realizadas determinações diárias do teor de $\mathrm{CO}_{2}$ liberado. No momento da avaliação, os frascos foram hermeticamente fechados com tampa de metal e septo de silicone por 30 minutos e amostras de $1 \mathrm{~mL}$ de gás do interior dos frascos eram coletadas utilizando-se seringa modelo Gastight, marca Hamilton de 2,5 mL. As amostras foram injetadas em cromatógrafo a gás (modelo Trace 2000/GC, marca Thermoffinigan), equipado com coluna Porapack $\mathrm{N}$ de $2 \mathrm{~m}$ de comprimento, metanador e detector de ionização de chama. $\mathrm{O}$ hidrogênio foi utilizado como gás de arraste a $40 \mathrm{~mL} \cdot \mathrm{min}^{-1}$. As temperaturas mantidas no aparelho foram de $100^{\circ} \mathrm{C}$ no injetor, $100^{\circ} \mathrm{C}$ para a coluna, $250^{\circ} \mathrm{C}$ no detector e $350^{\circ} \mathrm{C}$ no metanador. $\mathrm{O} \mathrm{CO}_{2}$ foi quantificado pela calibração com padrões de $2150 \mu \mathrm{L}$ $\mathrm{CO}_{2} \mathrm{~L}^{-1}$ e $29900 \mu \mathrm{L} \mathrm{CO} \mathrm{L}^{-1}$. Para o cálculo da respiração, foram 
considerados o volume do frasco, a massa dos frutos e o tempo de acúmulo de $\mathrm{CO}_{2}$. A taxa respiratória foi expressa em $\mathrm{mL}$ $\mathrm{CO}_{2} \mathrm{~kg}^{-1} \cdot \mathrm{h}^{-1}$. O procedimento para determinação da produção de etileno foi o mesmo utilizado para a determinação da taxa respiratória. A única diferença foi a temperatura do metanador, que, para esta determinação, foi de $100^{\circ} \mathrm{C}$. O etileno foi quantificado pela calibração com padrão de $1,94 \mu \mathrm{L} \mathrm{C}_{2} \mathrm{H}_{4} \mathrm{~L}^{-1}$. Os resultados foram expressos em $\mu \mathrm{L} \mathrm{C}_{2} \mathrm{H}_{4} \mathrm{~kg}^{-1} \cdot \mathrm{h}^{-1}$.

As maçãs MP dos diversos tratamentos foram mantidas sob refrigeração a $2{ }^{\circ} \mathrm{C}$ e avaliadas após $1,5,9$ e 13 dias de armazenamento. Nestes períodos, as avaliações realizadas foram: teor de umidade (INSTITUTO ADOLFO LUTZ, 1985); teor de sólidos solúveis; pH; e acidez total titulável segundo a AOAC (1992).

A dureza das amostras foi avaliada em texturômetro Texture Test System, modelo TP-1 acoplado a um registrador de variação de força, operando em célula padrão de compressão de cisalhamento CS-1, com 10 lâminas de 1/8 polegadas de espessura e ângulo de $90^{\circ}$. As amostras foram previamente pesadas (aproximadamente $50 \mathrm{~g}$ ) e colocadas na célula teste de cisalhamento e compressão, de tal forma que as lâminas das células tivessem ação paralela às amostras. Foi utilizado o sensor em $300 \mathrm{lbf}$ (libras-força) e a velocidade de descida do pistão foi de $20 \mathrm{~cm} / \mathrm{min}$. A força máxima de cisalhamento foi obtida da carta do registrador multiplicada pelo fator 3, que se refere à posição do sensor eletrônico, e dividida pelo peso da amostra. Os resultados foram expressos em libras força por grama $(\mathrm{lbf} / \mathrm{g})$.

A cor foi avaliada utilizando-se o Colorímetro Minolta, modelo Chroma Meter CR-200b. Foram utilizados 5 pedaços de maçãs em cada tratamento, realizando-se uma leitura por pedaço. As amostras foram avaliadas no sistema $\mathrm{L}, \mathrm{a}^{*} \mathrm{e} \mathrm{b}^{*}$ (BIBLE; SINGHA, 1993). O Índice de Escurecimento (IE) foi calculado de acordo com Palou et al. (1999), segundo a Equação 1:

$\mathrm{IE}=[100(\mathrm{X}-0,31)] / 0,172$

em que:

$\mathrm{X}=\left(\mathrm{a}^{\star}+1,75 \mathrm{~L}\right) /\left(5,645 \mathrm{~L}+\mathrm{a}^{\star}-3,02 \mathrm{~b}^{\star}\right)$.

\section{Análise estatística}

O delineamento experimental utilizado foi o inteiramente ao acaso em esquema fatorial $5 \times 4$, sendo 5 tratamentos (controle, solução conservadora, dextrina, fécula de mandioca e alginato de sódio) e 4 períodos de avaliação (1, 5, 9 e 13 dias de armazenamento refrigerado).

Nas análises físicas e físico-químicas realizadas, foram utilizadas 9 repetições em cada tratamento, exceto para a cor, em que foram utilizadas 5 repetições. Os resultados obtidos das avaliações físicas e físico-químicas foram submetidos à análise de variância pelo Teste $\mathrm{F}$, comparação de médias pelo Teste de Tukey (5\%), utilizando-se o sistema estatístico SAS (1989).

\section{Resultados e discussão}

$\mathrm{O}$ aspecto superficial dos produtos MP tratados com películas ficou muito semelhante, visualmente, aos das maçãs MP controle, ou seja, não aparentou apresentar recobrimento do tecido vegetal, com exceção do produto com alginato com cálcio, no qual a película formada foi mais espessa, brilhante e, também, mais visível macroscopicamente (Figura 1).

O aspecto superficial pode também ser visualizado pelas fotos obtidas em microscópio eletrônico de varredura (Figura 2).

Os produtos minimamente processados, como a própria definição (CANTWELL, 2000) determina, devem apresentar aspecto de fresco, ou seja, com todas as características físicas e fisiológicas de um produto in natura. Sensorialmente falando, o produto resultante do tratamento com alginato de sódio, não apresentou características de um produto in natura, mas sim, com aspecto de produto artificial, podendo ser rejeitado pelo consumidor como produto minimamente processado. No entanto, os aspectos fisiológicos da maçã MP apresentaram o alginato como a película que mais retardou o processo respiratório.

No $13^{\circ}$ dia de avaliação, as maçãs MP de todos os tratamentos apresentaram escurecimento (Figura 3).

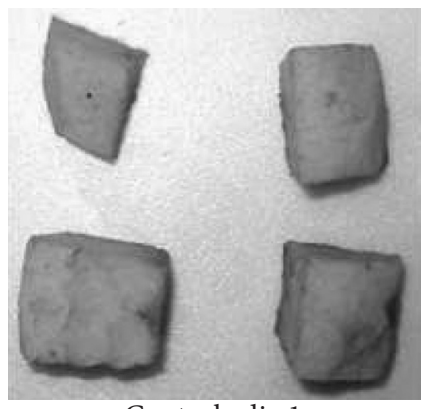

Controle dia 1

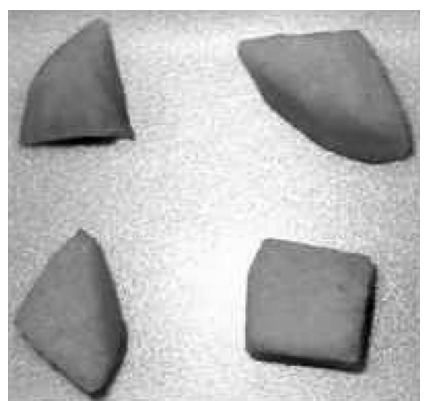

Dextrina

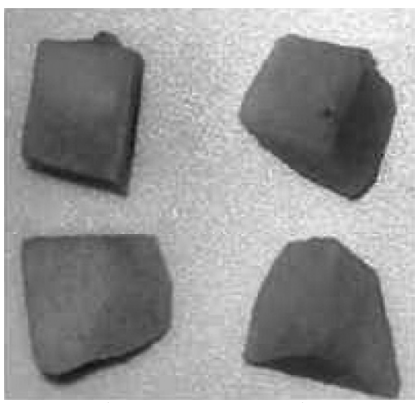

Solução conservadora

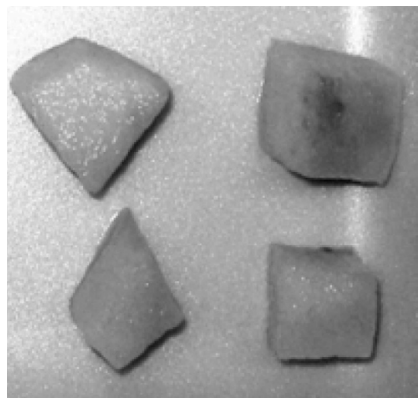

Fécula de mandioca

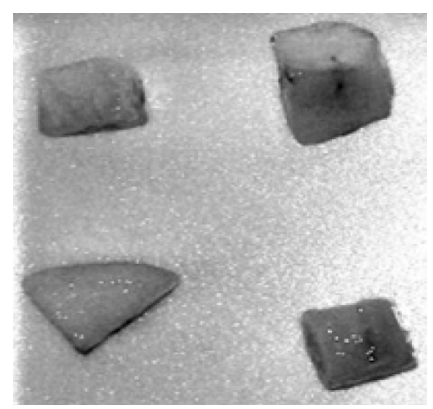

Alginato

Figura 1. Aspecto superficial (aparência) das maçãs MP após 1 dia de armazenamento refrigerado. 

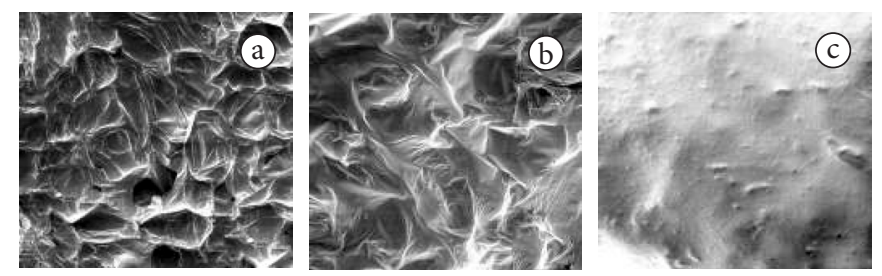

Figura 2. Micrografias das superfícies de maçãs MP que receberam tratamento de: a) dextrina de fécula de mandioca; b) fécula de mandioca; e c) alginato de sódio. Aumento de 100x.

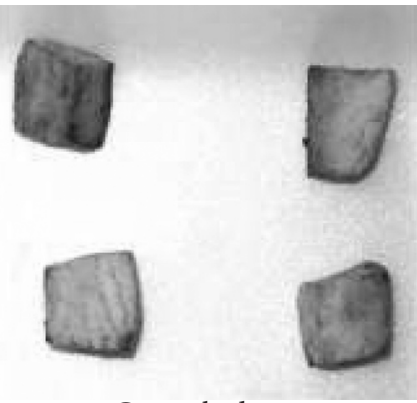

Controle dia 13

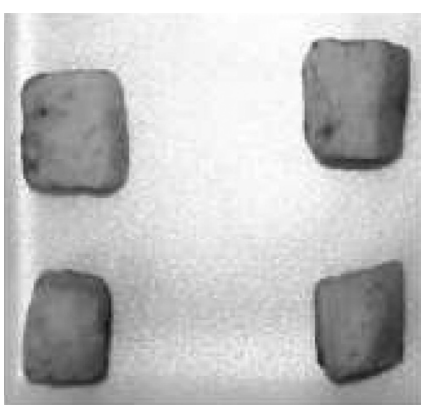

Dextrina

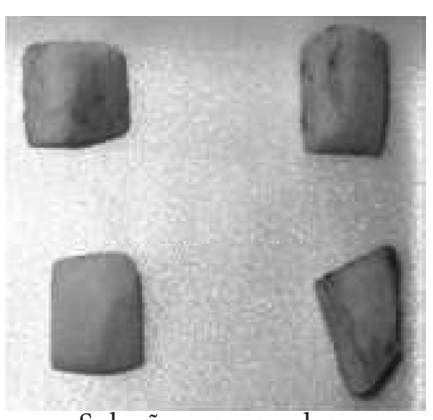

Solução conservadora

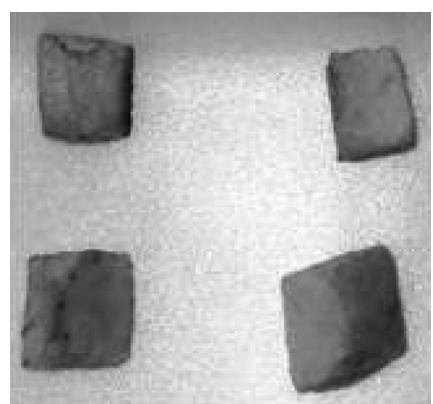

Fécula de mandioca

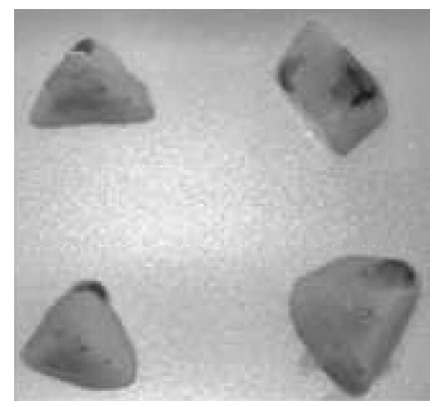

Alginato

Figura 3. Aspecto superficial (aparência) das maçãs MP após 13 dias de armazenamento refrigerado.

\subsection{Fisiologia das maçãs MP}

Os teores de $\mathrm{CO}_{2}$ liberados pelas amostras de cada tratamento durante o período de armazenamento refrigerado (Figura 4) apresentaram perfil com um pico respiratório no $2^{\circ}$ dia após o processamento das maçãs MP. Este pico, provavelmente, seja reflexo do estresse provocado pelo descascamento e corte do tecido, que causa perda da compartimentação celular e, com isto, os substratos do metabolismo respiratório entram em
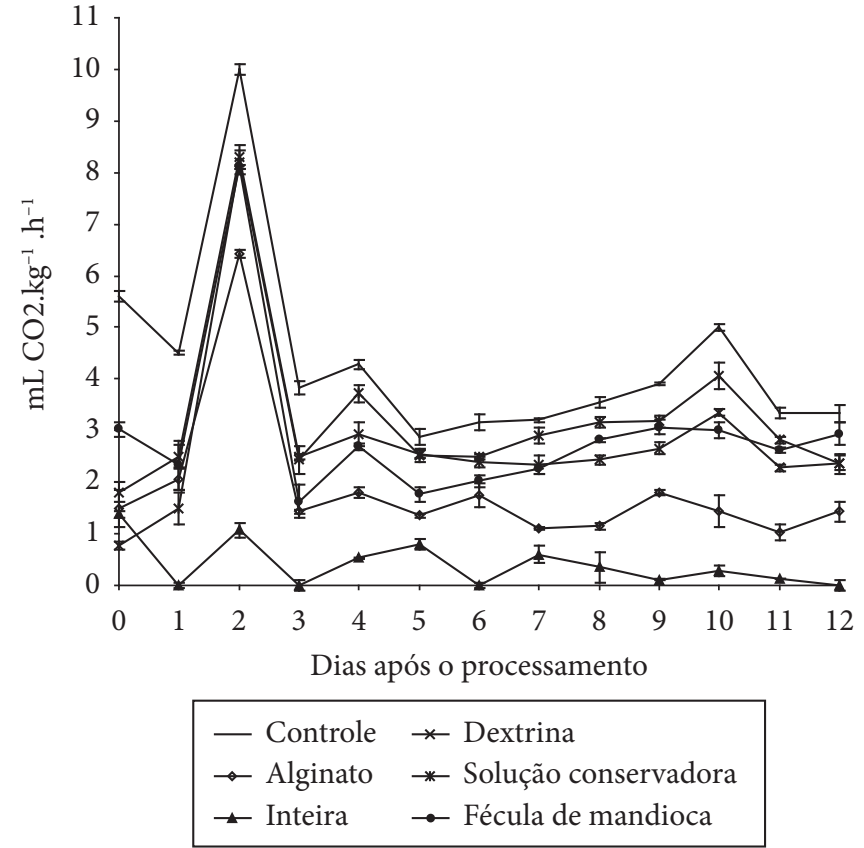

Figura 4. Taxa respiratória de maçãs MP sob diferentes tratamentos durante o armazenamento a $2{ }^{\circ} \mathrm{C}$.

contato com os complexos enzimáticos, resultando em incremento da taxa respiratória. Outra hipótese pode ser explicada pela resposta lenta das maçãs MP, que corresponde a reações biossintéticas, com formação de barreiras estruturais. Iniciam-se após uma ou várias horas e são respostas compartimentadas, ou seja, em nível de membranas, citosol ou paredes celulares. Embora inicialmente ocorra um "caos" celular, um padrão de resposta predizível e coordenada culmina com o fechamento do ferimento ao longo do tempo, usualmente após 3 a 4 dias do ferimento do tecido vegetal (CHITARRA, 2000).

A média dos valores de $\mathrm{CO}_{2}$ produzidos pelas amostras durante o armazenamento, desconsiderando o pico ( $2^{\circ}$ dia), foi utilizada para efeitos de comparação entre os tratamentos.

As maçãs MP apresentam valores médios entre 1,48 e $3,88 \mathrm{~mL} \mathrm{CO} \mathrm{kg}^{-1} \cdot \mathrm{h}^{-1}$, consideravelmente mais elevados que o das maçãs inteiras $\left(0,34 \mathrm{~mL} \mathrm{CO}_{2} \mathrm{~kg}^{-1} \cdot \mathrm{h}^{-1}\right)$, resposta já esperada em função da ativação de reações fisiológicas e bioquímicas devido à injúria dos tecidos.

O tratamento com película de alginato de sódio foi o mais eficiente dentre os tratamentos no controle da taxa respiratória das maçãs MP, apresentando média de $1,48 \mathrm{~mL} \mathrm{CO} \mathrm{kg}^{-1} \cdot \mathrm{h}^{-1}$. Este fato evidencia uma maior eficiência dessa película quanto ao controle das trocas gasosas, possivelmente em função de sua natureza, espessura ou formação de superfície contínua. A cobertura de fécula de mandioca apresentou a maior taxa respiratória $\left(3,19 \mathrm{~mL} \mathrm{CO}_{2} \mathrm{~kg}^{-1} \cdot \mathrm{h}^{-1}\right)$, seguida da cobertura de dextrina que apresentou taxa respiratória $\left(2,50 \mathrm{~mL} \mathrm{CO} \mathrm{kg}^{-1} \cdot \mathrm{h}^{-1}\right)$ dentre os tratamentos com película. Estes polímeros geram películas não eficientes para este fim, possivelmente com microbolhas de ar, que possibilitam trocas gasosas e, também, devido à sua menor espessura em relação à cobertura de alginato. 
Os biofilmes à base de polissacarídeos ou proteínas possuem excelentes propriedades mecânicas e ópticas, porém são sensíveis à umidade e apresentam alto coeficiente de permeabilidade ao vapor d'água e a gases (GONTARD; GUILBERT, 1996).

As maçãs MP tratadas com solução conservadora apresentaram média de $2,66 \mathrm{~L} \mathrm{CO}_{2} \mathrm{~kg}^{-1} \cdot \mathrm{h}^{-1}$, inferior às apresentadas pelas maçãs MP controle $\left(3,88 \mathrm{~mL} \mathrm{CO} \mathrm{kg}^{-1} \cdot \mathrm{h}^{-1}\right)$. Kato-Noguchi e Watada (1997), estudando cenouras MP observaram que a taxa respiratória foi substancialmente reduzida com a aplicação do ácido cítrico. O ácido cítrico está envolvido na inibição da enzima fosfofrutoquinase que catalisa a fosforilação da frutose 6-fosfato em 1,6-bifosfato na via glicolítica do metabolismo respiratório.

As maçãs MP revestidas com películas apresentaram taxa respiratória, em média, 1,6 vez menor que o tratamento controle. Uma redução da taxa respiratória também foi observada por Oliveira (1996), quando estudou goiabas inteiras tratadas com películas de fécula de mandioca a 1 e $2 \%$, armazenadas sob condições ambientes (19-27 ${ }^{\circ} \mathrm{C}$ e $59-76 \%$ UR) e por Kester e Fennema (1986), que aplicaram revestimento de éster de sacarose-carboximetilcelulose em bananas verdes. Estes últimos autores verificaram redução da permeabilidade ao oxigênio em 5 vezes e da permeabilidade ao dióxido de carbono em menos de 2 vezes.

As taxas de produção de etileno pelas maçãs MP durante o período experimental (Figura 5) mostram que no dia do processamento o corte dos tecidos alterou consideravelmente as taxas de liberação de etileno.

No $1^{\circ}$ dia de armazenamento, foi observado um maior percentual de queda na produção do gás etileno pelas maçãs, até mesmo para o fruto inteiro. Com o armazenamento, a redução na produção de etileno tendeu, no geral, a ocorrer em níveis menores até haver certa estabilização de valores no final do experimento.

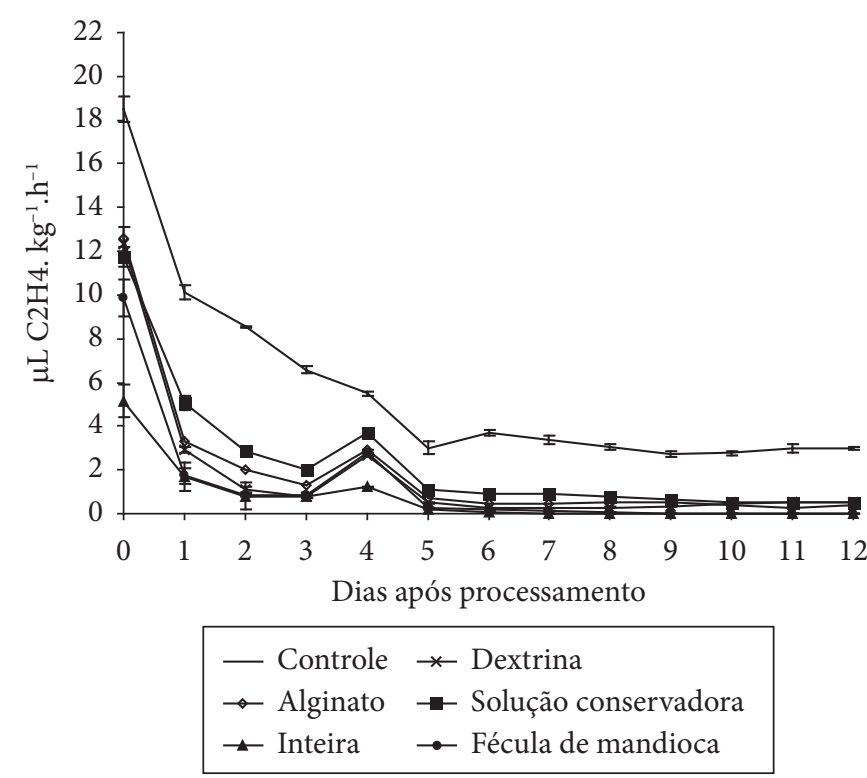

Figura 5. Produção de etileno pelas maçãs MP por diferentes tratamentos durante o armazenamento a $2{ }^{\circ} \mathrm{C}$.
Para efeitos de comparação, foi utilizada a média dos valores observados durante o armazenamento das amostras de cada tratamento, desconsiderando o pico do dia do processamento. Os tratamentos que apresentaram maiores taxas de produção de etileno, também apresentaram as maiores taxas respiratórias.

As maçãs MP dos tratamentos estudados apresentaram médias de produção de etileno variando de 0,88 a $4,61 \mu \mathrm{L} \mathrm{C} \mathrm{H}_{4} \mathrm{~kg}^{-1} \cdot \mathrm{h}^{-1}$, mais elevadas que as da maçã inteira $\left(0,39 \mu \mathrm{L} \mathrm{C} \mathrm{H}_{2} \mathrm{Hg}^{-1} \cdot \mathrm{h}^{-1}\right)$. Esses danos mecânicos advindos do processamento mínimo aumentam o metabolismo, com conseqüente aumento da síntese de etileno, causando maior velocidade de deterioração. O etileno proveniente do corte (etileno de ferimento) contribui para a biossíntese de enzimas envolvidas em alterações fisiológicas e bioquímicas associadas à senescência (BRECHT, 1995).

A taxa de produção de etileno do tratamento controle apresentou valor médio de $4,61 \mu \mathrm{L} \mathrm{C} \mathrm{C}_{4} \mathrm{~kg}^{-1} \cdot \mathrm{h}^{-1}$, superior ao da maçã MP imersa em solução conservadora que foi de $1,62 \mu \mathrm{L} \mathrm{C}_{2} \mathrm{H}_{4} \mathrm{~kg}^{-1} \cdot \mathrm{h}^{-1}$. Tanto o tratamento com a solução conservadora, como os de cobertura (fécula de mandio$\mathrm{ca}=0,57 \mu \mathrm{L} \mathrm{C}_{2} \mathrm{H}_{4} \mathrm{~kg}^{-1} \cdot \mathrm{h}^{-1}$; dextrina $=0,88 \mu \mathrm{L} \mathrm{C}_{2} \mathrm{H}_{4} \mathrm{~kg}^{-1} \cdot \mathrm{h}^{-1} \mathrm{e}$ alginato $=1,10 \mathrm{~L} \mathrm{C}_{2} \mathrm{H}_{4} \mathrm{~kg}^{-1} \cdot \mathrm{h}^{-1}$ ) reduziram a produção de etileno em mais de $50 \%$ em relação ao tratamento controle. Este comportamento evidencia a importância da solução conservadora no armazenamento de produtos MP, destacando-se o papel do ácido cítrico atuando no metabolismo vegetal e do cálcio, que atua, segundo Peroni (2002), possivelmente, como um enrijecedor do tecido superficial. As menores produções de etileno para maçãs tratadas com cloreto de cálcio também podem ser justificadas por estudo realizado por Mattoo e Suttle (1991), o qual afirma que o cálcio atua na biossíntese do etileno, inibindo a conversão do ácido 1-amino-ciclo-propano-carboxílico (ACC) para etileno.

Além da solução conservadora, o uso das películas foi eficiente, pois reduziu mais a taxa de produção de etileno, possivelmente devido à própria película que envolve a fruta poder gerar uma atmosfera modificada no fruto.

\subsection{Características físicas, químicas e físico-químicas das maçãs MP}

A perda de água dos frutos relaciona-se, principalmente, ao processo de transpiração, respiração e ao tempo de armazenamento, e resulta em enrugamento, amolecimento dos tecidos e perda de brilho, tornando os frutos mais susceptíveis às deteriorações. Também pode ocasionar alterações na cor e sabor deles (KADER, 1992).

Os teores de umidade, sólidos solúveis totais, $\mathrm{pH}$, acidez titulável e dureza das maçãs MP obtidas por diferentes tratamentos e armazenadas por diferentes tempos são apresentados na Tabela 1.

Os teores de umidade das maçãs MP variaram entre os tratamentos no $1^{\circ}$ e no $5^{\circ}$ dia de armazenamento e, depois, tenderam a se igualar. Dentre os tratamentos, o alginato tendeu a apresentar amostras mais úmidas no início do armazenamento. No $9^{\circ}$ e no $13^{\circ}$ dia, não foi constatada diferença entre os trata- 
Tabela 1. Valores médios de umidade, sólidos solúveis totais, pH e acidez titulável e firmeza das maçãs MP em função dos tratamentos e dos tempos de armazenamento.

\begin{tabular}{|c|c|c|c|c|c|c|}
\hline \multirow[t]{2}{*}{ Parâmetros } & \multirow{2}{*}{$\begin{array}{c}\text { Tempo } \\
\text { (dias) }\end{array}$} & \multicolumn{5}{|c|}{ Tratamentos } \\
\hline & & Controle & $\begin{array}{c}\text { Solução } \\
\text { conservadora }\end{array}$ & $\begin{array}{c}\text { Fécula } \\
\text { de mandioca }\end{array}$ & $\begin{array}{c}\text { Dextrina } \\
\text { de mandioca }\end{array}$ & $\begin{array}{l}\text { Alginato } \\
\text { de sódio }\end{array}$ \\
\hline \multirow[t]{3}{*}{ Umidade (\%) } & 1 & $85,32 \pm 0,29^{\mathrm{Ab}}$ & $85,87 \pm 0,31^{\mathrm{Ab}}$ & $87,76 \pm 0,07^{\text {Aab }}$ & $87,24 \pm 0,04^{\mathrm{Ab}}$ & $89,38 \pm 0,12^{\mathrm{Aa}}$ \\
\hline & 9 & $84,98 \pm 0,15^{\mathrm{Aa}}$ & $85,65 \pm 0,50^{\mathrm{Aa}}$ & $86,81 \pm 1,15^{\mathrm{Aa}}$ & $86,41 \pm 0,00^{\mathrm{Aa}}$ & $84,97 \pm 1,08^{\mathrm{Ba}}$ \\
\hline & 13 & $84,88 \pm 0,34^{\mathrm{Aa}}$ & $85,40 \pm 0,13^{\mathrm{Aa}}$ & $86,52 \pm 0,00^{\mathrm{Aa}}$ & $86,21 \pm 0,16^{\mathrm{Aa}}$ & $84,86 \pm 1,00^{\mathrm{Ba}}$ \\
\hline \multirow{2}{*}{$\begin{array}{l}\text { Sólidos Solúveis } \\
\left({ }^{\circ} \text { Brix }\right)\end{array}$} & 9 & $13,2 \pm 0,10^{\mathrm{Ba}}$ & $13,8 \pm 0,26^{\mathrm{Aa}}$ & $11,2 \pm 0,13^{\mathrm{ABb}}$ & $11,9 \pm 0,11^{\mathrm{ABb}}$ & $13,3 \pm 0,15^{\mathrm{Ba}}$ \\
\hline & 13 & $16,6 \pm 0,19^{\mathrm{Aa}}$ & $13,8 \pm 0,00^{\mathrm{Ab}}$ & $12,1 \pm 0,31^{\mathrm{Ac}}$ & $12,6 \pm 0,04^{\mathrm{Abc}}$ & $16,4 \pm 0,19^{\mathrm{Aa}}$ \\
\hline \multirow[t]{3}{*}{$\mathrm{pH}$} & 1 & $3,73 \pm 0,00^{\mathrm{Ab}}$ & $3,54 \pm 0,00^{\mathrm{Aa}}$ & $3,76 \pm 0,00^{\mathrm{Ab}}$ & $3,73 \pm 0,01^{\mathrm{ABb}}$ & $4,13 \pm 0,00^{A c}$ \\
\hline & 5 & $3,70 \pm 0,01^{\mathrm{Ab}}$ & $3,53 \pm 0,00^{\mathrm{Aa}}$ & $3,77 \pm 0,00^{\mathrm{Ab}}$ & $3,69 \pm 0,00^{\mathrm{Ab}}$ & $3,99 \pm 0,00^{A c}$ \\
\hline & 9 & $3,78 \pm 0,00^{\mathrm{ABb}}$ & $3,53 \pm 0,00^{\mathrm{Aa}}$ & $3,71 \pm 0,02^{\mathrm{Ab}}$ & $3,75 \pm 0,00^{\mathrm{ABb}}$ & $4,08 \pm 0,00^{A c}$ \\
\hline \multirow{2}{*}{$\begin{array}{l}\text { Acidez titulável } \\
(\mathrm{mL} \mathrm{NaOH} 0,1 \text { mol.L-1) }\end{array}$} & 9 & $0,48 \pm 0,00^{\mathrm{Aab}}$ & $0,52 \pm 0,00^{\mathrm{Aa}}$ & $0,42 \pm 0,02^{\mathrm{Aab}}$ & $0,39 \pm 0,00^{\mathrm{ABb}}$ & $0,27 \pm 0,02^{\mathrm{Bc}}$ \\
\hline & 13 & $0,45 \pm 0,01^{\mathrm{Ab}}$ & $0,55 \pm 0,00^{\mathrm{Aa}}$ & $0,44 \pm 0,00^{\mathrm{Aab}}$ & $0,43 \pm 0,00^{\mathrm{Ab}}$ & $0,36 \pm 0,02^{\mathrm{Ab}}$ \\
\hline \multirow{4}{*}{$\begin{array}{l}\text { Firmeza } \\
(\mathrm{lbf} / \mathrm{g})\end{array}$} & 1 & $3,62 \pm 0,11^{\mathrm{Aa}}$ & $3,17 \pm 0,19^{\mathrm{Ba}}$ & $1,83 \pm 0,10^{\mathrm{Bb}}$ & $2,01 \pm 0,09^{\mathrm{Bb}}$ & $2,11 \pm 0,02^{\mathrm{Bb}}$ \\
\hline & 5 & $2,99 \pm 0,01^{\mathrm{ABa}}$ & $3,67 \pm 0,17^{\mathrm{ABa}}$ & $2,31 \pm 0,12^{\mathrm{ABb}}$ & $2,31 \pm 0,19^{\mathrm{Bb}}$ & $2,36 \pm 0,00^{\mathrm{Abb}}$ \\
\hline & 9 & $2,87 \pm 0,02^{\mathrm{Bb}}$ & $4,17 \pm 0,15^{\mathrm{Aa}}$ & $2,56 \pm 0,18^{\mathrm{Ab}}$ & $2,58 \pm 0,17^{\mathrm{ABb}}$ & $2,59 \pm 0,00^{\mathrm{Ab}}$ \\
\hline & 13 & $2,53 \pm 0,09^{\mathrm{Bb}}$ & $4,48 \pm 0,01^{\mathrm{Aa}}$ & $2,88 \pm 0,00^{\mathrm{Ab}}$ & $2,90 \pm 0,06^{\mathrm{Ab}}$ & $2,60 \pm 0,19^{\mathrm{Ab}}$ \\
\hline
\end{tabular}

Médias seguidas de mesma letra minúscula na linha e maiúscula na coluna não diferem entre si, pelo Teste de Tukey em nível de $5 \%$ de probabilidade.

mentos. No início do armazenamento, o teor de umidade dos tratamentos com coberturas, geralmente mais elevados, pode indicar que a película estaria evitando a perda de umidade mais acentuada do momento do processamento para o $1^{\circ}$ dia de armazenamento. Outra hipótese seria o fato de que as películas podem reter em si parte da umidade existente no interior das embalagens de produtos MP, pois são hidrofílicas.

A maior concentração de sólidos solúveis é apresentada pelo controle, solução conservadora e alginato. As alterações entre os tratamentos se tornaram mais acentuadas no final do armazenamento $\left(13^{\circ} \mathrm{dia}\right)$, principalmente para o controle e alginato. A perda de umidade ocorrida nas maçãs tratadas com alginato no final do armazenamento pode ter sido da própria película, fazendo com que a concentração de sólidos permanecesse inalterada.

Os tratamentos com fécula de mandioca e dextrina resultaram em maçãs com menores teores de sólidos solúveis (SS) durante todo o período avaliado. A imersão das maçãs MP nestes tipos de solução filmogênicas poderia estar lixiviando os sólidos solúveis do vegetal.

Lima (1999), estudando maçãs inteiras da cv. Royal Gala armazenadas sob refrigeração, observou valores de teor de sólidos solúveis em torno de $10^{\circ} \mathrm{Brix}$, acidez titulável próximo de $0,33 \%$ de ácido málico, $\mathrm{pH} 4$ e firmeza $84,4 \mathrm{~N}$ no final do primeiro mês. O tempo de armazenamento alterou significativamente o teor de SS das maçãs MP, exceto para as tratadas com solução conservadora.
A acidez constitui fator de grande importância para o sabor e aroma dos frutos e, além disso, o pH influencia o escurecimento oxidativo dos tecidos vegetais. A diminuição do seu valor acarreta redução da velocidade de escurecimento do fruto (BRAVERMAN, 1967).

As maçãs MP com solução conservadora apresentaram valores de $\mathrm{pH}$ mais baixos em todos os tempos avaliados, possivelmente devido à constituição da solução utilizada (ácido ascórbico e ácido cítrico), cujo $\mathrm{pH}$ foi de 2,2. Os valores de $\mathrm{pH}$ das maçãs MP que receberam películas apresentaram valores de $\mathrm{pH}$ superiores, provavelmente em decorrência da interferência do $\mathrm{pH}$ das soluções filmogênicas. $\mathrm{O} \mathrm{pH}$ da solução de alginato foi igual a 7 .

Os tratamentos por solução conservadora, fécula de mandioca e alginato mantiveram o $\mathrm{pH}$ das frutas inalterado durante o armazenamento. Já as maçãs controle e a dextrina apresentaram tendência a aumento de $\mathrm{pH}$.

A acidez das maçãs apresentou comportamento inverso ao do $\mathrm{pH}$. As maçãs que receberam o tratamento com solução conservadora apresentaram os maiores valores de acidez. Os menores teores de acidez detectados nos demais tratamentos justificam-se pelas mesmas razões já explicadas para o $\mathrm{pH}$.

As maçãs MP apresentaram diferenças quanto à dureza entre os tratamentos, dentro de cada tempo de armazenamento e entre os tempos de armazenamento, para cada tratamento. 
As maçãs MP imersas em solução conservadora tenderam a apresentar maior firmeza que as dos demais tratamentos para cada tempo de armazenamento. Tal fato, possivelmente, seja justificado pela presença na solução conservadora do $\mathrm{CaCl}_{2}(0,25 \%)$, que pode promover o enrijecimento do tecido superficial. Embora os tratamentos com películas também tenham recebido esta solução, a imersão posterior, com as substâncias formadoras de revestimento pode ter diluído o cálcio, reduzindo seu efeito e gerando menores valores de textura (dureza).

No controle, foi verificada redução da firmeza com o armazenamento, tendência natural do tecido vegetal em função do tempo. Nos demais tratamentos que receberam adição de cálcio, a tendência foi oposta ao controle. No caso das maçãs MP com películas, a tendência ao seu enrijecimento pode estar sendo gerada pela tendência das macromoléculas, principalmente a dextrina e fécula de mandioca à retrogradação.

A cor das maçãs MP foi avaliada utilizando o sistema CIELab ou $\mathrm{L}, \mathrm{a}^{\star} \mathrm{e} \mathrm{b}^{\star}$, sendo o $\mathrm{L}$ a luminosidade que varia de 0 (preto) a 100 (branco) e "a" e "b" coordenadas de croma ( $-\mathrm{a}=$ verde, $+\mathrm{a}=$ vermelho, $-\mathrm{b}=$ azul $\mathrm{e}+\mathrm{b}=$ amarelo), ambas variando de -60 a +60 (BIBLE; SINGHA, 1993). Os valores de Luminosidade (L), croma $\mathrm{a}^{*} \mathrm{e} \mathrm{b}^{\star}$ das maçãs MP são apresentados na Tabela 2.

Em todos os tratamentos avaliados pode-se observar um aumento do índice de escurecimento em função do tempo de armazenamento. $\mathrm{O}$ tratamento controle foi o que apresentou valores maiores de índice de escurecimento; em contrapartida, o uso da solução conservadora foi eficiente, proporcionando o menor índice de escurecimento.
As polpas de maçãs MP com alginato apresentaram as menores médias de L (coloração mais escura) dentre os tratamentos, no entanto, tais valores não diferiram estatisticamente do tratamento controle a partir do $9^{\circ}$ dia e da dextrina ao $13^{\circ}$ dia. A coloração da solução de alginato, que é levemente marrom, e também do pH mais elevado dessas amostras podem ainda ter colaborado para este resultado.

Durante o armazenamento, os tratamentos com solução conservadora, fécula de mandioca e dextrina mantiveram a coloração das maçãs MP do $1^{\circ}$ dia, não ocorrendo escurecimento significativo. No entanto, o controle e o alginato de sódio apresentaram variação significativa dos valores de L, embora sem tendência definida no tempo.

Embora significativas, as variações do croma a* das maçãs MP dos diferentes tratamentos, os valores situaram-se próximos do eixo central, onde todas as cores se misturam, proporcionando uma coloração levemente marrom.

Após o $1^{\circ}$ dia de armazenamento, as maçãs MP controle apresentaram valores do croma $\mathrm{a}^{\star}$ maiores que os demais tratamentos, cujos valores foram semelhantes entre si. A partir do $9^{\circ}$ dia, entretanto, o tratamento controle se estabeleceu com os maiores valores do croma e o tratamento com solução conservadora com os menores valores.

Os tratamentos com películas apresentaram mudança significativa no croma $a^{*}$, evidenciando, a partir do $5^{\circ}$ dia de armazenamento, valores mais próximos do zero. No tratamento controle, o aumento foi verificado no $9^{\circ}$ dia de armazenamento e, para as maçãs imersas em solução conservadora, somente no $13^{\circ}$ dia de armazenamento.

Tabela 2. Valores médios de luminosidade, cromas $\mathrm{a}^{*} \mathrm{e} \mathrm{b}^{*} \mathrm{e}$ Índice de Escurecimento (IE) das maçãs MP em função dos tratamentos e dos tempos de armazenamento.

\begin{tabular}{|c|c|c|c|c|c|c|}
\hline \multirow{2}{*}{\multicolumn{2}{|c|}{$\begin{array}{c}\text { Tempo } \\
\text { (dias) }\end{array}$}} & \multicolumn{5}{|c|}{ Tratamentos } \\
\hline & & Controle & Solução & Fécula & Dextrina & Alginato \\
\hline \multirow[t]{4}{*}{$\mathrm{L}$} & 1 & $74,4 \pm 0,01^{\mathrm{Bab}}$ & $80,6 \pm 0,02^{\mathrm{Aa}}$ & $75,0 \pm 0,01^{\mathrm{Ba}}$ & $75,4 \pm 0,06^{\mathrm{ABa}}$ & $68,7 \pm 0,03^{\mathrm{Cab}}$ \\
\hline & 5 & $75,2 \pm 0,01^{\mathrm{Aa}}$ & $76,6 \pm 0,06^{\mathrm{Aa}}$ & $72,8 \pm 0,02^{\mathrm{Aa}}$ & $74,9 \pm 0,04^{\mathrm{Aa}}$ & $67,0 \pm 0,01^{\mathrm{Bb}}$ \\
\hline & 9 & $70,3 \pm 0,05^{\mathrm{BCab}}$ & $79,8 \pm 0,01^{\mathrm{Aa}}$ & $75,0 \pm 0,01^{\mathrm{Ba}}$ & $73,9 \pm 0,08^{\mathrm{Ba}}$ & $66,8 \pm 0,01^{\mathrm{Cb}}$ \\
\hline & 13 & $69,5 \pm 0,09^{\mathrm{Cb}}$ & $81,0 \pm 0,01^{\mathrm{Aa}}$ & $75,2 \pm 0,01^{\mathrm{Ba}}$ & $74,9 \pm 0,01^{\mathrm{BCa}}$ & $73,2 \pm 0,01^{\mathrm{BCa}}$ \\
\hline \multirow[t]{4}{*}{$a^{*}$} & 1 & $-2,0 \pm 0,01^{\mathrm{Ab}}$ & $-5,2 \pm 0,10^{\mathrm{Bb}}$ & $-4,2 \pm 0,01^{\mathrm{Bb}}$ & $-4,5 \pm 0,01^{\mathrm{Bb}}$ & $-4,2 \pm 0,02^{\mathrm{Bb}}$ \\
\hline & 5 & $-0,8 \pm 0,01^{\mathrm{Ab}}$ & $-3,4 \pm 0,01^{\mathrm{Bb}}$ & $-2,5 \pm 0,04^{\mathrm{ABab}}$ & $-1,6 \pm 0,01^{\mathrm{Aa}}$ & $-2,0 \pm 0,01^{\mathrm{Aa}}$ \\
\hline & 9 & $1,5 \pm 0,02^{\mathrm{Aa}}$ & $-3,3 \pm 0,01^{\mathrm{Cb}}$ & $-1,1 \pm 0,01^{\mathrm{Ba}}$ & $-1,0 \pm 0,01^{\mathrm{Ba}}$ & $-1,6 \pm 0,01^{\mathrm{Ba}}$ \\
\hline & 13 & $2,6 \pm 0,07^{\mathrm{Aa}}$ & $-2,7 \pm 0,04^{\mathrm{Ca}}$ & $-1,2 \pm 0,01^{\mathrm{Ba}}$ & $-0,3 \pm 0,01^{\mathrm{Ba}}$ & $-1,3 \pm 0,01^{\mathrm{Aa}}$ \\
\hline \multirow[t]{4}{*}{$b^{*}$} & 1 & $36,6 \pm 0,10^{\mathrm{Aa}}$ & $27,2 \pm 0,01^{\mathrm{Bb}}$ & $28,1 \pm 0,01^{\mathrm{Bb}}$ & $28,0 \pm 0,01^{\mathrm{Bb}}$ & $22,8 \pm 0,01^{\mathrm{Cb}}$ \\
\hline & 5 & $34,0 \pm 0,01^{\mathrm{Ab}}$ & $30,1 \pm 0,01^{\mathrm{Ba}}$ & $30,6 \pm 0,01^{\mathrm{Ba}}$ & $32,7 \pm 0,01^{\mathrm{ABa}}$ & $23,8 \pm 0,01^{\mathrm{Cb}}$ \\
\hline & 9 & $35,7 \pm 0,01^{\mathrm{Aab}}$ & $31,2 \pm 0,01^{\mathrm{Ba}}$ & $30,0 \pm 0,02^{\mathrm{Ba}}$ & $33,2 \pm 0,01^{\mathrm{Aa}}$ & $29,6 \pm 0,01^{\mathrm{Ba}}$ \\
\hline & 13 & $34,9 \pm 0,07^{\mathrm{Ab}}$ & $30,6 \pm 0,01^{\mathrm{Ba}}$ & $31,9 \pm 0,03^{\mathrm{Ba}}$ & $33,1 \pm 0,06^{\mathrm{Aa}}$ & $30,5 \pm 0,00^{\mathrm{Ba}}$ \\
\hline \multirow[t]{4}{*}{ IE } & 1 & $62,8 \pm 0,17^{\mathrm{Ab}}$ & $34,9 \pm 0,12^{\mathrm{Bb}}$ & $41,3 \pm 0,06^{\mathrm{Bb}}$ & $40,2 \pm 0,15^{\mathrm{Bb}}$ & $34,3 \pm 0,11^{\mathrm{Bc}}$ \\
\hline & 5 & $67,0 \pm 0,11^{\mathrm{Aa}}$ & $45,3 \pm 0,09^{\mathrm{Ba}}$ & $50,1 \pm 0,19^{\mathrm{Ba}}$ & $54,0 \pm 0,13^{\mathrm{ABa}}$ & $40,1 \pm 0,18^{\mathrm{Bb}}$ \\
\hline & 9 & $68,2 \pm 0,12^{\mathrm{Aa}}$ & $44,6 \pm 0,08^{\mathrm{Ca}}$ & $54,7 \pm 0,11^{\mathrm{Ba}}$ & $49,9 \pm 0,18^{\mathrm{BCa}}$ & $54,8 \pm 0,15^{\mathrm{Ba}}$ \\
\hline & 13 & $69,8 \pm 0,17^{\mathrm{Aa}}$ & $43,3 \pm 0,02^{\mathrm{Ca}}$ & $52,4 \pm 0,19^{\mathrm{Ba}}$ & $55,7 \pm 0,16^{\mathrm{Ba}}$ & $50,8 \pm 0,01^{\mathrm{Ba}}$ \\
\hline
\end{tabular}

Médias seguidas de mesma letra minúscula na coluna e maiúscula na linha não diferem entre si, pelo Teste de Tukey em nível de $5 \%$ de probabilidade. 
Os valores de croma b* das maçãs MP apresentaram-se positivos, ou seja, mais próximos do amarelo. Ocorreram alterações do croma $b^{*}$ das maçãs MP durante o armazenamento para os tratamentos que não o controle, mostrando maior aumento de intensidade do amarelo entre o $1^{\circ}$ e o $5^{\circ}$ dia de armazenamento e depois, menos acentuadamente.

A Tabela 3 apresenta os níveis de correlação entre as variáveis luminosidade, cromas $\mathrm{a}^{*} \mathrm{e} \mathrm{b}^{*}$, índice de escurecimento, firmeza, umidade, $\mathrm{pH}$ e acidez titulável, abordadas nas Tabelas 1 e 2 .

Segundo Sounis (1975), o índice de correlação apresenta interdependência entre duas variáveis, podendo ser uma correlação positiva, quando o aumento de uma variável implica em aumento da outra ou vice versa, e negativa, quando os comportamentos das variáveis são inversos. O mesmo autor enfoca que um índice acima de 0,7 pode ser considerado elevado, enquanto o intervalo de 0,5 a 0,7 é médio e, abaixo de 0,5 , seria um baixo índice de correlação.

A solução conservadora apresentou maçãs MP com tendência a colorações mais claras ao longo do armazenamento (Tabela 2). Este fato pode estar associado à presença de agentes antioxidantes e branqueadores na solução e também ao menor $\mathrm{pH}$ da fruta que acarreta um menor escurecimento da polpa, evidenciado pela correlação negativa entre o valor L e o $\mathrm{pH}$ e positiva entre a acidez titulável e o valor $\mathrm{L}$ novamente (Tabela 3).

O tratamento controle apresentou maiores valores do croma $b^{*}$ desde o $1^{\circ}$ dia de armazenamento, entretanto, com o avanço dos dias, tendeu a se aproximar dos valores das maçãs com película de dextrina (Tabela 2). O menor amarelecimento dos demais tratamentos pode ser em função do uso de solução conservadora ou de um escurecimento oxidativo mais intenso das maçãs controle logo após o corte (antes do $1^{\circ}$ dia de armazenamento). Tal fato pode-se evidenciar pelo elevado índice de correlação entre os valores $\mathrm{a}^{\star} \mathrm{e}^{\star}$ e entre estes e o índice de escurecimento (Tabela 3).

Tabela 3. Correlação entre as variáveis físicas e físico-químicas (luminosidade, croma $\mathrm{a}^{*} \mathrm{e}^{*}$, índice de escurecimento e firmeza, umidade, pH e acidez titulável) de maçãs MP em função dos tratamentos e dos tempos de armazenamento.

\begin{tabular}{lc}
\multicolumn{1}{c}{ Variáveis } & Índice de correlação \\
\hline $\mathrm{a}^{*} \times \mathrm{b}^{*}$ & 0,7 \\
$\mathrm{a}^{*} \times$ Índice de Escurecimento & 0,9 \\
$\mathrm{~b}^{*} \times$ Índice de Escurecimento & 0,9 \\
$\mathrm{~b}^{*} \times$ Umidade & $-0,8$ \\
$\mathrm{~L} \times \mathrm{pH}$ & $-0,9$ \\
$\mathrm{~L} \times$ Acidez Titulável & 0,6 \\
L x Firmeza & $-0,6$ \\
Índice de Escurecimento x Umidade & $-0,6$ \\
Umidade x Acidez titulável & $-0,6$ \\
$\mathrm{pH} \times$ Acidez Titulável & $-0,6$ \\
$\mathrm{pH} \times$ Firmeza & 0,9 \\
\hline
\end{tabular}

\section{Conclusões}

O uso de solução conservadora e películas comestíveis reduziram o processo respiratório e a produção de etileno em maçãs em relação ao tratamento controle, com melhor destaque para os tratamentos com alginato de sódio.

Maçãs MP revestidas com alginato apresentaram menor acidez, além de coloração mais escura da polpa.

As Maçãs MP tratadas com alginato de sódio, não apresentaram características de produto in natura, podendo ser rejeitadas pelo consumidor como produto minimamente processado.

No tratamento controle, foi verificada redução dos valores de firmeza do produto ao longo do armazenamento. Nos demais tratamentos que receberam adição de cálcio, a firmeza dos tecidos de maçãs MP foi aumentando com o tempo.

O uso da solução conservadora resulta em maçãs MP com menores índices de escurecimento e sem alteração da cor natural.

\section{Referências bibliográficas}

ASSOCIATION OF OFFICIAL ANALYTICAL CHEMISTS. Official methods of analysis. 14 ed. Washington: Association of Official Analytical Chemists, 1992. $1141 \mathrm{p}$.

BALDWIN, E. A.; NISPEROS-CARRIEDO, M. O.; BAKER, R. A. Use of ediblecoatings to preserve quality of lightly (and slightly) processed products. Critical Reviews in Food Science and Nutrition, v. 35, n. 6, p. 509-524, 1995a.

BIBLE, B. B.; SINGHA, S. Canopy position influences CIELAB coordinates of peach color. HortScience, v. 28, n. 10, p. 992-993, 1993.

BRAVERMAN, J. B. S. Introducción a la bioquimica de los alimentos. Barcelona: Omega, 1967. 355p. Cap.14.

BRECHT, J. K. Physiology of lightly processed fruits and vegetables. HortScience, v. 30, n. 1, p. 18-22, 1995.

CANTWELL, M. The dynamic fresh-cut sector of the horticultural industry. In:ENCONTRO NACIONALSOBRE PROCESSAMENTO MÍNIMO DE FRUTAS E HORTALIÇAS, 2, 2000, Viçosa. Palestras... Viçosa: UFV, Viçosa, 2000. p. 147-155.

CHIEN, P. J.; SHEU, F.; YANG, F. H. Effects of edible chitosan coating on quality and shelf life of sliced mango fruit. Journal of Food Engineering, v. 78, n. 1, p. 225-229, 2007.

CHITARRA, M. I. F. Processamento mínimo de frutas e hortaliças. Lavras: UFLA/FAEPE, 2000. 113p.

GIL, M. I.; GORNY, J. R.; KADER, A. A. Responses of "Fuji" apple slice to ascorbic acid treatments and low oxygen atmospheres. HortScience, v. 33, n. 2, p. 305-309, 1998.

GONTARD, N.; GUILBERT, S. Bio-packing: Technology and properties of edible and/or biodegradable material of agricultural origin. Boletim da SBCTA, v. 30, n. 1, p. 3-15, 1996.

INSTITUTO ADOLFO LUTZ. Normas analíticas do instituto Adolfo Lutz. 3 ed. São Paulo: IAL, 1985. 533p. v. 1.

KADER, A. A. Postharvest technology of horticultural crops. 12 ed. Oakland: University of California, Division of Agriculture and Natural Resources, 1992. 296p.

KATO-NOGUCHI, H.; WATADA, A. E. Citric acid reduces the respiration of fresh cut carrots. HortScience, v. 32, n. 1. p. 136, 1997. 
KESTER, J. J.; FENNEMA, O. R. Edible films and coatings: a review. Food Technology, v. 40, n. 12, p. 47-59, 1986.

KROCHTA, J. M.; MULDER-JOHNSTON, C. Edible and biodegradable polymer films: challenges and opportunities. Food Technology, v. 51, n. 2, p. 61-74, 1997.

LEE, J. Y.; PARK, H. J.; LEE, C. Y.; CHOI, W. Y. Extending shelf life of minimally processed apples with edible coatings and antibrowning agents. Lebensmittel Wissenchaft und Technology, v. 36, p. 323-329, 2003

LIMA, L. C. Armazenamento de maçãs cv. Royal Gala sob refrigeração e atmosfera controlada. Lavras, 1999. 96 f. Dissertação - (Mestrado em Ciências dos Alimentos) - Universidade Federal de Lavras.

MATTOO, A.; SUTTLE, J. C. The plant hormone ethylene. Boca Raton: CRCPress, 1991. 337 p.

MORETTI, C. L. Processamento mínimo de hortaliças: alternativa viável para a redução de perdas pós-colheita e agregação de valor ao agronegócio brasileiro. Horticultura Brasileira, v. 17, n. 2, p. 1, 1999.

NUSSINOVITCH, A.; HERSHKO, V. Gellan and alginate vegetable coatings. Carbohydrate Polymers, v. 30, n. 2-3, p. 185-192, 1996.

OLIVEIRA, M. A. Utilização de películas de féculas de mandioca como alternativa à cera comercial na conservação pós-colheita de frutos de goiaba (Psidium guava) variedade Kumagai. Piracicaba, 1996. 73 f. Dissertação - (Mestrado em Ciência e Tecnologia de Alimentos) - Escola Superior de Agricultura "Luiz de Queiroz", Universidade de São Paulo, 1996.

PALOU, E. et al. Polyphenoloxidase activity and color of blanched and high hydrostatic pressure treated banana puree. Journal of Food Science, v. 64, n. 1, p. 42-45, 1999.

PERONI, K. M. C. Influência do cloreto de cálcio sobre a vida de prateleira de melão "amarelo" minimamente processado. Lavras, 2002. 86 f. Dissertação - (Mestrado em Ciências dos Alimentos), Universidade Federal de Lavras, 2002.

SAS/IML. Software: usage and reference. Version 6. Cary, 1989. 501p.

SOUNIS, E. Bioestatística: princípios fundamentais, metodologia estatística aplicação às ciências biológicas. 2 ed. São Paulo: McGrawHill, 1975.

VIEIRA, A. P.; VIEITES, R. L.; EVANGELISTA, R. M. Película de fécula de mandioca no abacaxi minimamente processado. In: CONGRESSO BRASILEIRO DE CIÊNCIA E TECNOLOGIA DE ALIMENTOS, 17, 2000. Anais... Fortaleza: SBCTA, 2000. p. 3-61.

WONG, D. W. S. et al. Gas exchange in cut apples with bilayer coatings. Journal of Agriculture and Food Chemistry, v. 42, n. 10, p. 2278-2285, 1994. 